\title{
Self-Monitoring of Blood Cholesterol (SMBC) using the Total Cholesterol Testing Cartridge on the 1 drop $^{\text {TM }}$ Smartphone
}

\author{
Bolodeoku J ${ }^{1 *}$, Clark $\mathbf{S}^{1}$ and Anyaeche $\mathrm{C}^{2}$ \\ ${ }^{1}$ JB Consulting MDP Limited, 1 Bell Street, Maidenhead, Berkshire, SL6 1BU, UK \\ ${ }^{2}$ Pathaway Services Limited, Headlands House, 1 Kings Court, Kettering, NN15 6WU, UK \\ *Corresponding author: Bolodeoku J, JB Consulting MDP Limited, 1 Bell Street, Maidenhead, Berkshire, SL6 1BU, UK
}

\begin{tabular}{|c|c|}
\hline ARTICLE INFO & ABSTRACT \\
\hline $\begin{array}{l}\text { Citation: Bolodeoku J, Clark S, Anyaeche } \\
\text { Self-Monitoring of Blood Cholesterol } \\
\text { SMBC) using the Total Cholesterol Testing } \\
\text { Cartridge on the } 1 \text { drop }^{\text {TM }} \text { Smartphone. } \\
\text { 3iomed J Sci \& Tech Res 29(2)-2020. BJSTR. } \\
\text { MS.ID.004760. }\end{array}$ & $\begin{array}{l}\text { The } 1 \mathrm{drop}^{\mathrm{TM}} \mathrm{TC} \text { is a total cholesterol testing device smartphone (Galaxy J3) with } \\
\text { a specially designed mobile application that measures total cholesterol. In this pilot } \\
\text { study, we evaluated the performance (intra-individual variation, intra-assay precision } \\
\text { and comparative data) of the } 1 \mathrm{drop}^{\mathrm{TM}} \text { smart phone in measuring total cholesterol. } 1 \\
\text { drop }^{\mathrm{TM}} \text { Smartphone is a smart phone used to determine total cholesterol. In this pilot } \\
\text { study, on a healthy volunteer, the } 1 \text { drop }^{\mathrm{TM}} \text { demonstrated a within in person variation } \\
\mathrm{CV} \% \text { of total cholesterol of } 7.3 \% \text { and an intra-assay precision of } 6 \% \text {. In the comparative } \\
\text { study, the total cholesterol estimates of the } 1 \text { drop }{ }^{\mathrm{TM}} \text { device were on average } 6 \%, 13 \% \\
\text { and } 23 \% \text { more than the total cholesterol estimates of the Mission, Prima } 3 \text { in } 1 \text { and } \\
\text { CardioChek, respectively. There was no statistical difference between the estimates } \\
\text { apart from estimates of the CardioChek. The specifications of the } 1 \text { drop }{ }^{\mathrm{TM}} \text { smartphone } \\
\text { are comparable with the handheld self-monitoring blood cholesterol testing devices } \\
\text { and further evaluations, with an expansion in lipid profile, would make it a potential } \\
\text { for home monitoring. }\end{array}$ \\
\hline
\end{tabular}

\section{Introduction}

There are a number of hand-held cholesterol testing devices such as the CardioChek, Mission, 3in1 available. These devices measure a range of lipid fractions such as the Total Cholesterol (TC), Low Density Lipoprotein Cholesterol (LDL-C), High Density Lipoprotein Cholesterol (HDL-C) and Triglyceride (TG). One of the challenges that these hand-held self-monitoring devices such as the Mission; CardioChek and the 3in1 need to overcome to take their place in clinical practice, is the ability to transmit the data. Smart phones have data transmission capabilities using Global Systems for Mobile Communication (GSM); Wireless Fidelity (WiFi); bluetooth and Universal Serial Bus (USB), making it easy to transfer the information from point of test to a centralized location where this information can be viewed by the specialist [1]. In addition, latest smart phone developments, with the use of built in or external sensors and devices to enable sample application and testing, have placed them at the centre of point of care testing
$[1,2]$. Recently, the elemark ${ }^{\mathrm{TM}}$ lipid check, a smart phone based point of care device for self-testing of a lipid profile with transmission capabilities was described. This device can store and send the result of the measurements to a server where the patient's clinician can gain access to the information. It was shown to correlate very well with hospital laboratory tests $(r>0.97, p<0.001)$ for all threecholesterol blood tests: TC, HDL-C and TG [3]. We have performed a few studies on the device and found the precision of the elemark ${ }^{\mathrm{TM}}$ comparable to that of the CardioChek and it had an acceptable biological variation for TC, HDL-C and TG $[4,5]$. Current advances have led to the development of the smart CARD - smartphone Cholesterol Application for Rapid Diagnostic system, making it possible to measure total cholesterol. The test cartridge is fitted over the camera and the inbuilt flash provides uniform diffused light to illuminate the test strip. An application on the smart phone calibrates the image colour values on the test strip and the results appear on the phone. This device was shown to measure total 
cholesterol comparable to the estimations made by the CardioChek [6]. The $1 \mathrm{drop}^{\text {TM }} \mathrm{TC}$ is a total cholesterol testing device smartphone (Galaxy J3) with a specially designed mobile application that measures total cholesterol. In this pilot study, we evaluated the performance (intra-individual variation, intra-assay precision and comparative data) of the $1 \mathrm{drop}^{\mathrm{TM}}$ smart phone in measuring total cholesterol.

\section{Materials}

a) $1 \mathrm{drop}^{\mathrm{TM}}$ Smart phone and total cholesterol test strip x 25 - The $1 \mathrm{drop}^{\mathrm{TM}} \mathrm{TC}$ is a testing system used for determination of the total amount of cholesterol in whole blood. The system consists of a specially designed mobile application, which is installed in the smart phone (Galaxy J3), with the specially designed smartphone cover and membrane containing dried reagents (1 drop $^{\mathrm{TM}}$ TC total cholesterol test cartridge) see Figure 1.

b) Capillary blood samples (Healthy Volunteer)

c) CardioChek PA device and lipid profile test strips $x 8$

d) Prima 3in 1 Cholesterol Meter and total cholesterol test strips $\mathrm{x} 8$

e) Mission ACON Cholesterol Meter and lipid profile test strips $x 8$

\section{Method}

Total cholesterol estimation using $1 \mathrm{drop}^{\mathrm{TM}}$.

a) Step 1 - Insert the test strip cartridge into the chamber over the camera on the smart phone

b) Step 2 - Apply a drop of blood on to the strip sensor

c) Step 3 - Check the results on the smartphone application d) Step 4 - Result displayed on smart phone screen in $\mathrm{mg} / \mathrm{dl}$

The mean physiological day to day variation study was evaluated with capillary blood samples collected from single subject between 08.00 and 10.00am on days $1,2,3,4,5,6,7,8,9,10,11,12,13,14$ $\& 15,16$ and 17 and total cholesterol estimated as described on the self-testing lipid point of care testing device: $1 \mathrm{drop}^{\mathrm{TM}}$ following the steps outlined previously. The intra-assay precision study was estimated by taking a capillary blood sample into a tube from the subject between 08.00 and 10.00am on day 11. Seven samples were tested from the aliquot for total cholesterol as described on the selftesting lipid point of care testing device: $1 \mathrm{drop}^{\mathrm{TM}}$ following the steps outlined previously. The intra-assay precision study was calculated out using mean, standard deviation (SD), coefficient of variation (CV), coefficient of variation percent (CV\%). The comparative study was performed using capillary blood samples collected from single subject on Days 10,11,12,13,14,15,16* \& 17 and run on the following self-testing lipid point of care testing devices: 1 drop, the CardioChek PA, Prima and the Mission ACON for Total Cholesterol on Days according to their manufacturer's instructions. The means of the total cholesterol estimations were calculated, the SD and Students Tests was applied to see if there was a statistical difference between the total estimates of the devices. *Second sample taken on day 16 separate from sample for biological variation.

\section{Results}

Within Person Variation (see Figure 1). On days 1 to 17 , the total cholesterol values estimated ranged between $4.1 \mathrm{mmol} / \mathrm{L}$ $-7.38 \mathrm{mmol} / \mathrm{L}$ (Figure 2). The within person variation CV\% of total cholesterol in this healthy volunteer using the 1 drop was estimated as $14.6 \%$. However, this includes results on days 5 and 6 which are clear outliers. When the results of days 5 and 6 are excluded the CV\% estimate was calculated as $7.2 \%$ (Table 1 ).

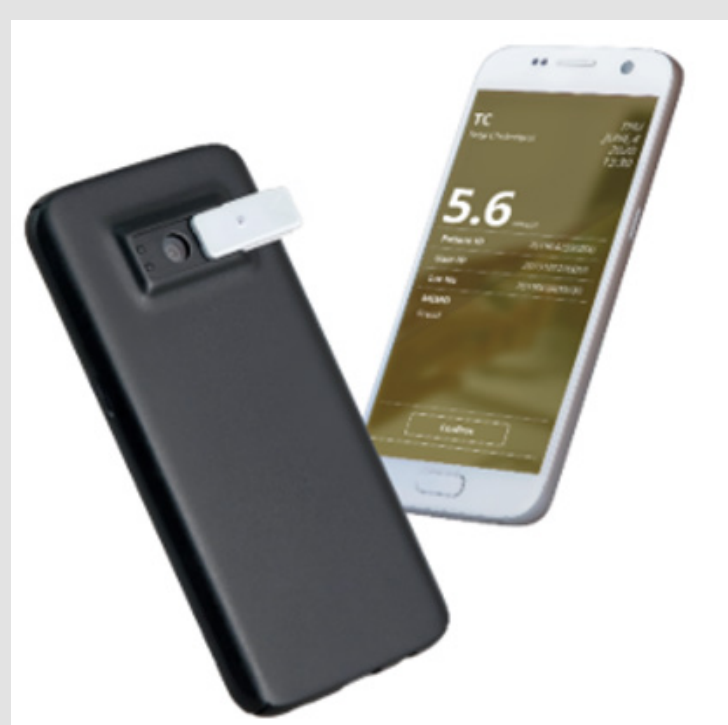

Figure 1: Figure showing photograph Galaxy J3 with the specially designed smartphone cover and membrane containing dried reagents (1drop ${ }^{\mathrm{TM}} \mathrm{TC}$ total cholesterol test cartridge). 


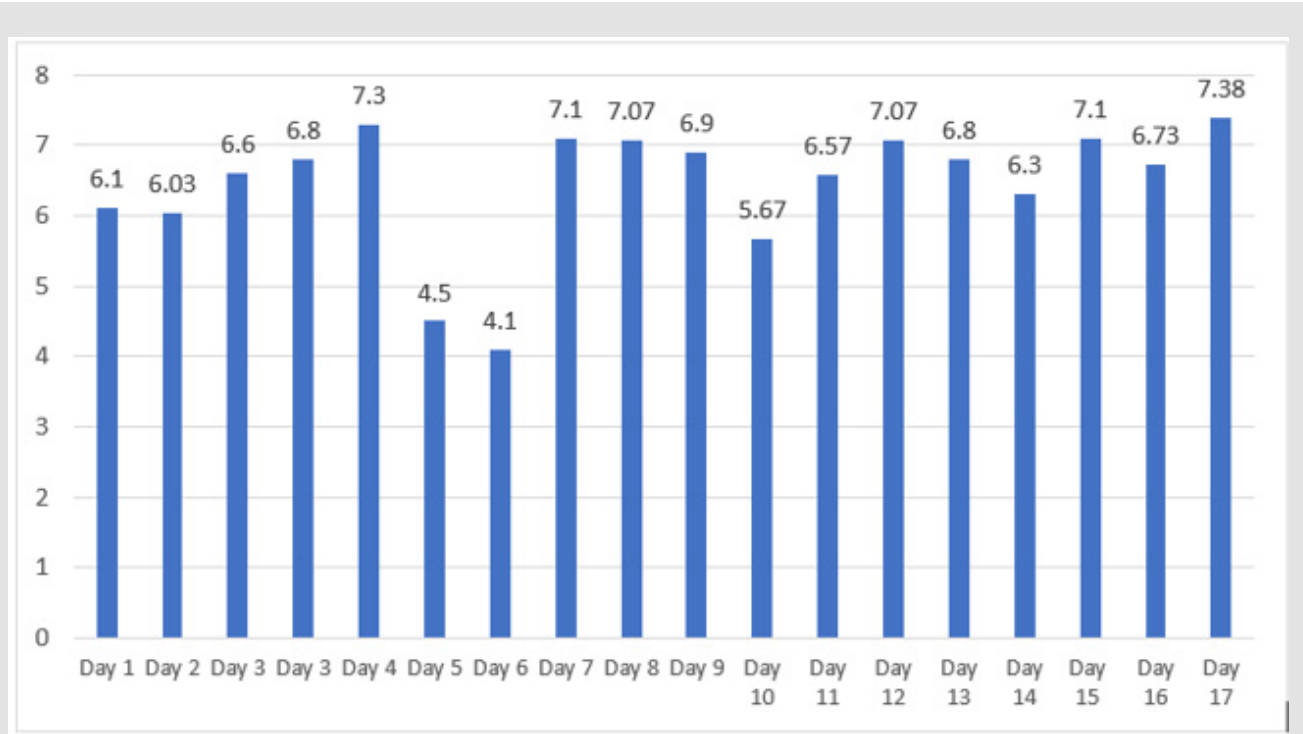

Figure 2: Showing the daily total cholesterol estimations using the 1 drop ${ }^{\mathrm{TM}}$ smart phone in the healthy volunteer.

Table 1: Showing the CV\% of the total cholesterol estimations using the $1 \mathrm{drop}^{\mathrm{TM}}$ smart phone.

\begin{tabular}{|c|c|c|c|}
\hline & Mean & SD & CV\% \\
\hline With outliers & 6.451111111 & 0.930483521 & 14.42361642 \\
\hline Without outliers & 6.72 & 0.485135644 & 7.219280422 \\
\hline
\end{tabular}

\section{Intra-Assay Precision}

On day 11 , seven estimations on the collected capillary whole blood sample, these estimations are seen in table 2. The intra-assay precision study was calculated out using mean, SD, and CV\%. The intra-assay precision was calculated as $5.9 \%$.

Table 2: Showing the CV\% of the total cholesterol estimations using the 1 drop ${ }^{\mathrm{TM}}$ smart phone.

\begin{tabular}{|c|c|}
\hline & Day 11 \\
\hline & 6.57 \\
\hline & 6.68 \\
\hline & 6.57 \\
\hline & 6.01 \\
\hline Mean & 6.06 \\
\hline SD & 7.09 \\
\hline CV\% & 6.78 \\
\hline
\end{tabular}

\section{Comparative Study}

The total cholesterol estimates of the 1 drop $^{\text {TM }}$ device were on average $6 \%$ more than the total cholesterol estimates of the Mission device. The difference between the estimates ranged from $-1.39 \mathrm{mmol} / \mathrm{L}$ to $+1.16 \mathrm{mmol} / \mathrm{L}$. However, there was no statistical difference between the two sets of estimates using the $T$ Test $(p=0.2)$ (Figure 3). The 1 drop $^{\mathrm{TM}}$ device total cholesterol estimates were on average $13 \%$ more than the total cholesterol estimates of the Prima 3in1. The difference between the estimates ranged from $-+0.6 \mathrm{mmol} / \mathrm{L}$ to $+2.48 \mathrm{mmol} / \mathrm{L}$. There was no statistical difference between the two sets of estimates using a T Test, but it was just borderline ( $\mathrm{p}=0.049$ ) (Figure 4). The 1 drop $^{\mathrm{TM}}$ device total cholesterol estimates were on average $23 \%$ more than the total cholesterol estimates of the CardioChek. The difference between the estimates ranged from $-0.6 \mathrm{mmol} / \mathrm{L}$ to $+2.48 \mathrm{mmol} / \mathrm{L}$. In addition, there was a statistical difference between the two sets of estimates using a T Test $(\mathrm{P}<0.0001)$ (Figure 5). 


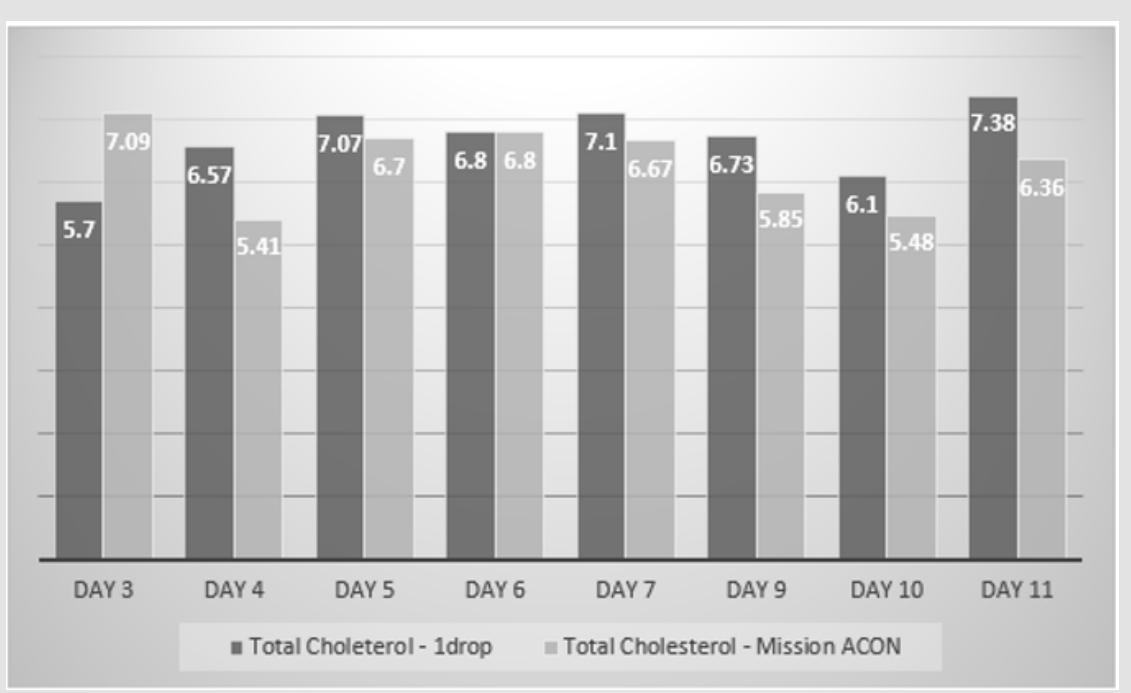

Figure 3.

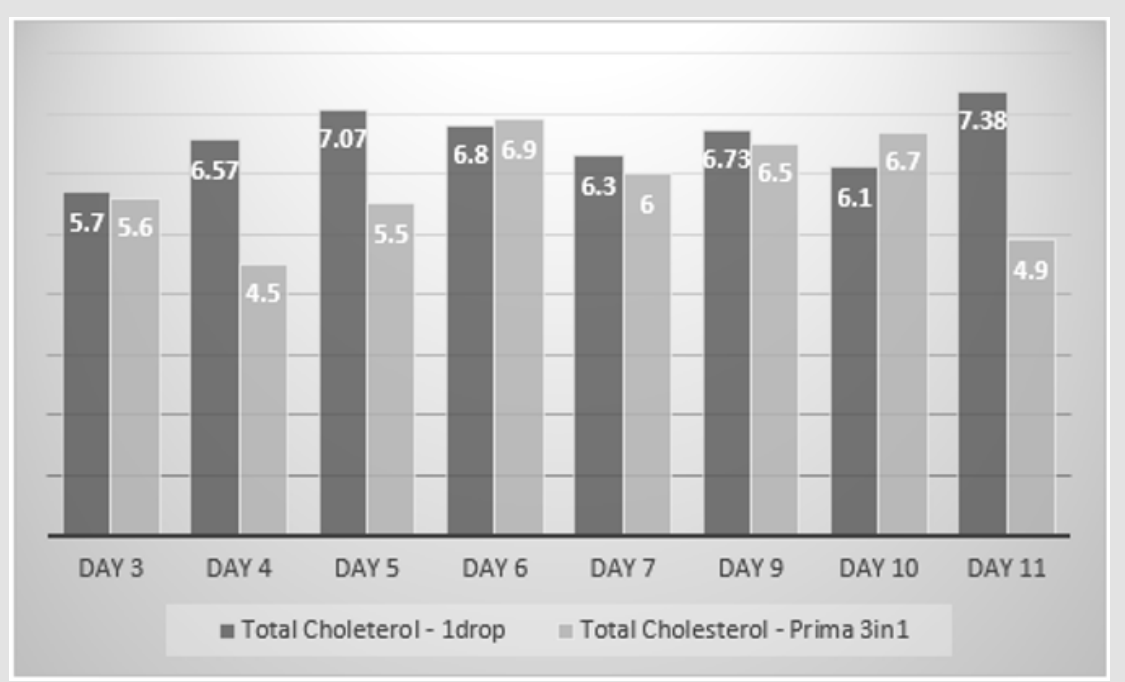

Figure 4.

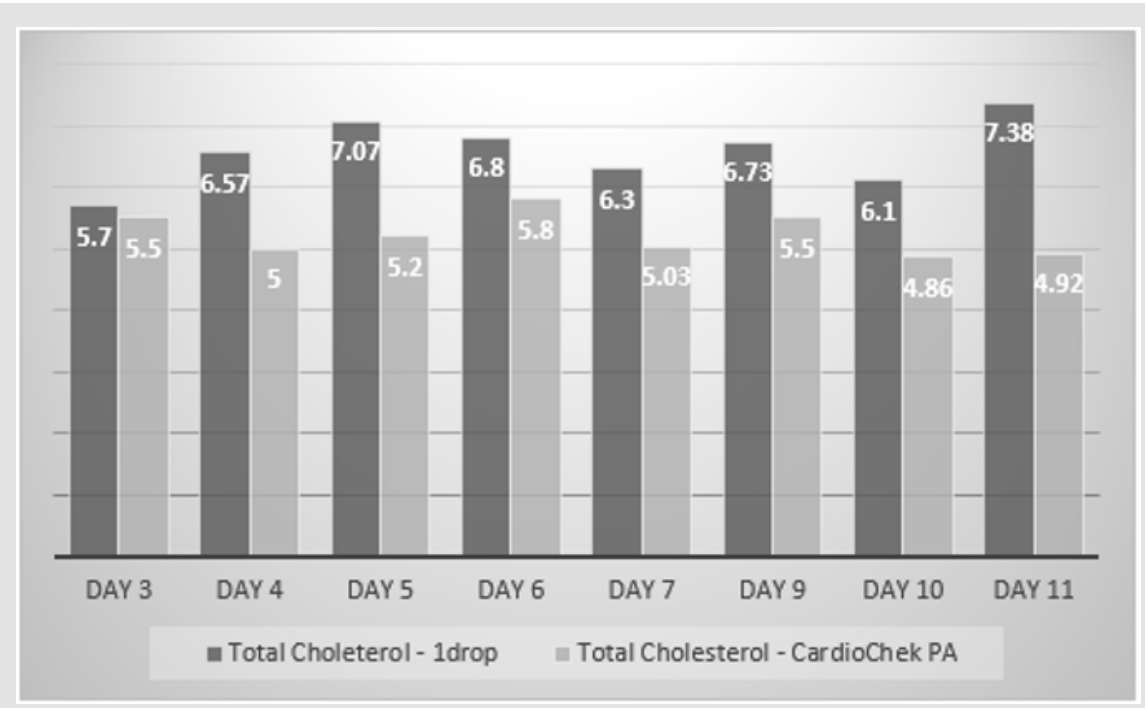

Figure 5. 


\section{Discussion}

In this pilot study looking at the specifications (within person variation, intra-assay precision and comparison) of the $1 \mathrm{drop}^{\mathrm{TM}}$ smart-phone total cholesterol testing device in a healthy subject, we found that the intra individual variation of $7.2 \%$ obtained, to be quite consistent with what we have previously found with other hand held self-monitoring cholesterol testing devices such as the Prima 3in1 (7.0\%), CardioChek (9.4\%) and the elemark ${ }^{\mathrm{TM}}(5.0 \%) 5$. Furthermore, this is also consistent with the daily variation seen in the sera of healthy subjects which is expected to be $2.5 \%-10.9 \%$ [710]. The intra-assay precision of $5.9 \%$ of the 1 drop $^{\mathrm{TM}}$ smart-phone total cholesterol testing device was consistent with the information on the product literature $(4.2 \%-6.7 \%)$ and what we found in other hand-held cholesterol self-testing devices such as the CardioChek $(5.4-8.3 \%)$ and the elemark ${ }^{\mathrm{TM}}(3.0 \%-5.3 \%)$ [4]. Although $1 \mathrm{drop}^{\mathrm{TM}}$ smart-phone total cholesterol testing device intra-assay precision was consistent with other devices, it was higher than the $3 \%$ recommended by the National Cholesterol Education Program (NCEP) and Cholesterol Reference Method Laboratory Network (CRMLN) [11,12]. In the comparative part of the study, the estimates of the $1 \mathrm{drop}^{\mathrm{TM}}$ device were closest to the estimates of the Mission device. The average difference was $6 \%$ and there was no statistical difference between the estimates. However, the estimates using the CardioChek device had the largest average difference of $-23 \%$ when compared to the estimates of the $1 \mathrm{drop}^{\mathrm{TM}}$ and they were statistically significant. The observation with the CardioChek is quite consistent with all our other studies where the CardioChek estimates have been compared with other devices. In this study, comparing the CardioChek, Prima 3in1 and the elemark ${ }^{\mathrm{TM}}$ (a hand-held smart device testing cholesterol), the elemark ${ }^{\mathrm{TM}}$ had the highest total cholesterol mean estimates of $5.74 \mathrm{mmol} / \mathrm{L}$, followed by the Prima 3in 1 with a mean estimate of $5.00 \mathrm{mmol} / \mathrm{L}$ and then the CardioChek with a mean estimate of $4.24 \mathrm{mmol} / \mathrm{L} 5$.

In this study, we have been able to demonstrate that the $1 \mathrm{drop}^{\mathrm{TM}}$ total cholesterol smartphone testing device has an acceptable intra-individual variation, intra-assay precision and compares well with other hand-held cholesterol testing devices. Self-monitoring of blood cholesterol, with these devices, has been shown to be beneficial. In a randomized study in patients being treated for their hyperlipidaemia, one group of patients were given the CardioChek to measure and report their lipid levels over a 6 month period by telephone and the other group had their lipid levels measured in the traditional laboratory setting. The results showed that both groups showed comparable reductions in their LDL-C, HDL-C and TG levels and there was no significant difference observed between the two groups [13]. We look forward to more studies in the real world setting to demonstrate using such devices as the 1 drop and believe that the future clinical practice will include the use of such devices as the $1 \mathrm{drop}^{\mathrm{TM}}$ used routinely in the management of patients on cholesterol lowering treatment.

\section{References}

1. Xu X, Akay A, Wei H, Wang S, Pingguan-Murphy B (2015) Advances in smartphone-based point of care diagnostics. Proceeding of the IEEE 103(2): 236-247.

2. Kanchi S, Sabele MI, Mdluli PS, Inamuddin M, Bisetty K (2018) Smartphone based bioanalytical and diagnosis applications: A review Biosensors and Bioelectronic 102: 136-149.

3. Yun K, Lee J, Choi J, Song IU, Chung YA (2019) Smartphone based point of care lipid blood test performance evaluation compared with a clinical diagnostic laboratory method Applied Science 9(16): 3334.

4. Bolodeoku J, Pinkney S (2019) Imprecision evaluation of self-monitoring of blood cholesterol (SMBC) handheld point of care testing devices: Elemark $^{\mathrm{TM}}$ and CardioChek PA. Ann Clin Lab Res 7(1): 290.

5. Bolodeoku J (2018) Biological Variation of Self-Monitoring of Blood Cholesterol (SMBC) Using Portable Handheld Point of Care Testing Devices: 3in1, Cardiochek PA and Elemark. Curr Trends Med Diagn Meth.

6. Oncscu V, Mancuso M, Erickson D (2014) Cholesterol testing on a smartphone Lab Chip 14: 759-763.

7. Hammond J, Wentz P, Statland BE, Phillips JC, Winkel P (1976) Daily variation of lipids and hormones in sera of healthy subjects. Clinica Chimica Acta 73(2) : 347-352.

8. Demacker PNM, Schade RWB, Jansen RTP, Laar AV (1982) Intraindividual variation of serum cholesterol triglycerides and high density lipoprotein cholesterol in normal humans. Atherosclerosis 45(3): 259266.

9. Gidding SS, Stone NJ, Bookstein LC, Laskarzewski PM, Stein EA (1998) Month to month variability of lipids, lipoproteins and apolipoproteins and the impact of acute infection in adolescents. The Journal of Pediatrics 133(2): 242-246

10. Bookstein L, Gidding SS, Donovan M, Smith FA (1990) Day to day variability of serum cholesterol, triglyceride, and high density lipoprotein cholesterol levels. Arch Intern Med 150(8) : 1653-1657.

11.(1988) National Cholesterol Education Program Laboratory Standardization Panel. Current status of blood cholesterol measurement in clinical laboratories in the US. Clin Chem 34: 193-201.

12.(1995) National Cholesterol Education Program Laboratory Standardization Panel. Recommendations for measurement of high density lipoprotein cholesterol; executive summary. Clin Chem 41: 1427-1433.

13. Alkouli MA, Carry BJ, Jarrett H, Sirna SJ (2013) Management of hyper cholesterolaemia utilizing a home lipid monitoring system, preliminary findings. J Clin Lipid 7(3) : 254-255. 
ISSN: $2574-1241$

DOI: 10.26717/BJSTR.2020.29.004760

Bolodeoku J. Biomed J Sci \& Tech Res

(C) This work is licensed under Creative

Submission Link: https://biomedres.us/submit-manuscript.php

$\begin{array}{ll}\text { BIOMEDICAL } & \text { Assets of Publishing with us } \\ \text { RESEARCHES } & \text { - Global archiving of articles } \\ \text { - Immediate, unrestricted online access } & \text { - Rigorous Peer Review Process } \\ & \text { - Authors Retain Copyrights } \\ & \end{array}$

